\title{
María Puig de la Bellacasa (2017) Matters of Care: Speculative Ethics in More Than Human Worlds. Minneapolis and London: University of Minnesota Press. 265 pages. ISBN: 978-1-5179-0064-9
}

\author{
Sonja Jerak-Zuiderent \\ s.jerak-zuiderent@amc.uva.nl
}

The book Matters of Care: Speculative Ethics in More Than Human Worlds is about involvement; not about getting involved, but about how we are already always involved in one way or the other, together with "objects, other animals, living beings, organisms, physical forces, spiritual entities, and [other] humans" (p. 1)- whether we want it or not. This means the book does not propose that care is a resource that can be added to the world through scholarship; it is already there and we are implied in it. And, if we follow the suggestion of María Puig de la Bellacasa, "speculative exploration of the significance of care" (p. 1) involves attending to care as it is already going on in, often neglected, practices. This means that "the 'ethics' in an ethics of care cannot be about a realm of normative moral obligations but rather about thick, impure, involvement in a world where the question of how to care needs to be posed" ( $p$. 6). With care being inherently situated and normatively ambivalent, it would need to be quite present in our research.

And yet... "Nobody has ever asked me this... It is a question that you do not get very often."That is the response I got when recently, in interviewing a philosopher, I asked her what she cares about in her research. I was paraphrasing the central question in Matters of Care about how to do our research 'as well as possible'. The reply shows that this book serves a real need.
If scholars are no longer posing the question what they care about, let alone about how they are "putting in the work to 'care for'" (p. 5), this may be because we get increasingly used to the question of 'the good' in academia as suspect. Questions of goods now come with a set of standard answers, and new externalized criteria that we must start adhering to. Yet those standard answers and external criteria reduce our capacities to imagine good science. I keep coming across (at least) four standard responses which suggest measures to warrant the concern for the academic good:

1. through procedures and the mushrooming developments on research ethics and integrity, including proposals to introduce something like an 'integrity passport' for academics';

2. through a combination of performance and assessment measures like the $\mathrm{h}$-index and an increased quest for excellence;

3. through enhanced transparency of the research process, for example through 'open data' requirements about making findings available in repositories, and

4. through focusing on the (envisioned) impact of scholarship on society.

With all such answers, most people feel a little uncomfortable. They itch. But many of us scratch and move on. Many feel we have to 'play the game'. And each of these standard responses provides some form of comfort by externalizing the 
question; reducing complex STS analytic textures to sometimes seemingly productive strategies. Others keep on scratching by repeating how all such standard answers stay within an oft-trodden neoliberal-welfare-governance-state trope-trail. But whether scratching briefly or continuously; scratching often makes the itching worse and keeps the exploration of alternatives at bay.

Matters of Care proposes a radically different response to the question of how to respond to issues of ethos in research. Puig de la Bellacasa offers analytical sensitivities for how to do research 'as well as possible'. The book then is essential reading for all those who feel there must be better answers, better reasons for why they ended up as scholars - or getting trained as such; particularly scholars who find kin amongst others focused on STS questions and concerns. But, although this is an important reason to read the book, this is not what it is about.

Puig de la Bellacasa, rather than prescribing what the good in academia (or anywhere else) could be about, offers with Matters of Care a richness of sensitivities to realize - taking the double meaning of the word literally - our always already ongoing involvement in more than human worlds and the possibilities and obligations this realization of involvement entails. This 'matter-ialised' involvement, she argues, lies in realizing neglected possibilities and obligations to disrupt implicit or explicit splits between thinking and living in more than human worlds. The book elaborates in two parts how to realize our involvement. First, it argues for a thorough re-imagination of 'knowledge politics'; not by offering yet another turn - a turn to care, but rather by refreshing the moral and political value of care by scrutinizing the historically trodden paths of feminist and STS-companionships for vital complications of neglected matters. The second part is situating the conceptual consequences of a knowledge politics with care into the relational webs in naturecultures. Puig de la Bellacasa shows that our imagination of technoscience and naturecultures materialize in our (in)capacities of living in difference together in more than human worlds. This imagination refers also to concepts that are organized collectively as a '(common) good' - for example, academia, democracy, economies, nation states, communities.
Taking this argument seriously - that to realize our possibilities and obligations of living in difference together in more than human worlds materialises in the often neglected, situated potential of affective, ethical, and hands-on agencies of practical and material consequences in the ecologies of our research - how and whom does it help to think of the academic good as being part of a game or of a collective excellence sportdiscipline? And at what costs do we play such a game and compete to excel? And is there a way to not ignore the involvement and obligation to "the specificity of moments, particular relations, of ecologies where the ethical is both personal agency and embedded in the 'ethos' of a community" (p. 151) without "defining in advance a code of conduct or a normative definition of right and wrong" (p. 152)? As in the h-index, the integrity passport, the open data repository, or the measured impact of modern scientific practices.

Although grand narratives are ubiquitous and particularly promising in policy terms, Matters of Care encourages us to confidently resist the rhetoric of playing the game of 'solving problems' by responding to any question - be it academic malpractice, poverty, racism, ecological crisis like climate change, wars - in standard ways or by pretending that our particular research is not directly related to the textures of more than human worlds it is situated in. Thinking our research lives with care, we realize our involvement by learning to firmly slow down, to complicate attempts of grand epics by paying attention to situatedness and its neglected possibilities, neglected temporalities in the "living mesh" (p. 20) of the everyday in research life.

Slowing down during the recent interviews I made concerning good science/research ${ }^{2}$ proved quite generative: Once people pause at the question, some start highlighting things and situations they care about, that involve the work of 'caring for', and that according to them are part of good research but that are somewhere lost outside the research-project-cycle that increasingly dominates our imagination. The interlocutors, for example, referred to moments such as not immediately rushing off after having given a lecture for PhD students and postdocs, and leaving their office door open to invite their questions related to their unfolding research 
lives. These moments are not about transferring knowledge to 'recipients', but speak about knowing that happens somewhere in between the mesh of the everyday. These examples might not be surprising to anyone, because they do take place and many of us do things like that or similar things like regular walking seminars or writing retreats. However, what is surprising, is that these everyday moments of good research are completely absent from the general debates and concerns about good science. What makes it so hard to articulate these everyday moments in such debates, but that at the same time very much contribute to the 'as well as possible' of science?

Articulating such fleeting practices as Matters of Care identifies is a way to argue for and at the same time to nurture, a politics of not only showing versions of 'as well as possible' worlds that are already ongoing, but also how these get neglected. Situating this argument in a texture of companion stories of feminist technoscience work, Puig de la Bellacasa shows how this requires the capacity to appreciate the tension of thinking and living an ethos entailed in situatedness.

In terms of the situatedness of this review, I pause for a moment at open data; one of the emerging ways to warrant good science within and across disciplines. Although medical sciences and pharmaceutical industry have unfortunately proven to us that it is a good idea to make transparent what kind of knowledge politics gets promoted by 'following the money', extrapolating this approach to all scholarly fields may well be disastrous. It would surely not help to "unhinge some of the moral rigidities" (p. 11) of externalized research ethics. Open data explicitly neglects the complications that the notion of 'data' brings with it, and can therefore fuel accelerations in a problem-solving data-science-world. By letting go of situatedness as a firm stance, such data-scienceworlds-thinking risks damage to and ultimately destruction of, the circulation of care as "a thick mesh of relational obligation" (p. 20) cultivated by for example not running away after the lecture, keeping the office door open, walking seminars or writing retreats.

Care thus becomes paying attention to such neglected moments, but also about learning to ask different questions about data, for example about why we think machine learning will lead to better care robots, but not questioning the argument that having humans carry out that care would be too expensive, as Lucy Suchman (2018) recently did. Or about why the moment data exploration is done by pregnant women who are given access to their records, their assiduity and concerns about the many missing data points in their records get classified by professionals as bothersome, which raises, as Brit Ross Winthereik (2018) recently did, the question about the spaces for patients in data work and the stark contrast with promises of open data.

Matters of Care are thus not developed through establishing dividing lines between concepts, thinkers or disciplines, but rather through speculatively intervening through relating multifarious commitments to situatedness. Puig de la Bellacasa develops and lives her argument in Matters of Care symmetrically in how she re-presents it. She moves from thinking/living with care in technoscience to thinking/living with care in naturecultures - while emphasising that this order is not prioritizing thinking/concepts before substance.

It is in the rich second part of engaging with everyday ecologies of sustaining and perpetuating life while moving through it, that I would have loved to learn more of; the "living mesh" ( $p$. 20 ) of the knower who thinks and lives through the bumpy circulations between thinking/ living with care and thinking/living through care. Although it is not developed as such and in some way even defies development, I see in the emphasis on the continuous search for "ways of thinking that engage care" (p. 18) also a relational obligation towards the knower as a living mesh. Engaging "more substantially and deeply in telling stories around experientially observed and researched terrains" (p. 21) can then not 'merely' make "(...) the complexities of thinking with care even more intricate" (p. 21); it offers also the possibility to explore the neglected epistemic potential of the "affective, ethical, and hands-on agencies of practical and material consequence" (p. 4) of our thinking. Not by splitting it from the substances of our everyday research lives, but rather by developing a similar sensitivity for the invisible work that constitutes our knowing through "affective, 
ethical, and hands-on agencies of practical and material consequence" (p. 4) of thinking and living.

Appreciating the initial itching as instantiation of 'ontological disconcertment' (Verran, 2001) about academic goods (and bads) may help point to even thicker possibilities to tell "involved stories, neither theoretical nor descriptive, open to alternative readings, yet situated" (p. 22). Appreciating itching offers a possibility to avoid "[t]he fatal flaw in (...) standard STS analytics" of conceptualizing the STS scholar "as removed observer" (Verran, 2017: 20) and rather think and live a two-wayness of concepts not only between the knower and her mind (Verran, 2016) but also between the knower and the specificities of the ecologies that the knowing emerges from. This allows us, for example, to attend to the neglected possibilities and obligations to think and live academia in neoliberal democratic nation states and economies with care - troubling "the democratic assembly of articulate concerns as well as generat[ing] possibility" (p. 18). Matters of Care offers tentative guidance that is novel in its ability to attend to what is already there. The book is a crucial resource for all those who prefer groundcaring over ground-breaking scholarship.

\section{References}

Ross Winthereik B (2018) "Seeing Through Infrastructure: Ethnographies of Health IT, Development Aid, Energy, and Data". Inaugural Professorial Lecture at the ITU Copenhagen, Denmark, March 23rd, 2018.

Suchman L (2018) "The Fantasy of Social Robots: Reconfiguring the Future of Care Technologies". Receiving an Honorary Doctorate at Maastricht University and Giving a Keynote Lecture on the Symposium: The Future of a Data-Driven Society, Maastricht University, January 25 ${ }^{\text {th }}, 2018$.

Verran H (2001) Science and an African Logic. Chicago: University of Chicago Press.

Verran H (2016) "Towards Good Organisational Policy for Organisational Goods". Opening Keynote Lecture at the Organizational, Learning, Knowledge and Capabilities conference, University of St Andrews, Scotland, April $27^{\text {th }}, 2016$.

Verran H (2017) "Matters of Fact(ization), Matters of Capitalization, and Matters of Care", EASST, Vol 36/No 1: $19-20$.

\section{Notes}

1 Suggested as a possibility in a presentation during the conference in Bonn, Germany, Why Research Integrity Matters to You, February 5-7, 2018.

2 These interviews are part of a project on Achieving Good Science - A Cross-disciplinary Study that I am involved in - Project leader Jeannette Pols and Amade M'charek, and Jonna Brenninkmeijer and myself as project investigators; financed by the Netherlands Organisation for Health Research and Development (ZonMW). 